\title{
PENAMBAHAN SERBUK LIMBAH KACA DAN ABU DAUN BAMBU TERHADAP KINERJA PAVING BLOCK
}

\author{
Anita Intan Nura Diana ${ }^{1)}$ dan Subaidillah Fansuri ${ }^{1)}$ \\ 1) Program Studi Teknik Sipil, Universitas Wiraraja, Sumenep, Jawa Timur \\ anita@wiraraja.ac.id
}

\begin{abstract}
Glass is an object that cannot be separated from human life. Based on data from the Minister of Environment and Forestry (LHK) in 2020, it was stated that data on waste in Indonesia reached 67.8 million tons, of which 0.7 million tons were glass waste. It is known that the types of waste produced in Indonesia are organic waste (60\%), plastic waste (14\%), paper waste (9\%), metal (4.3\%), glass and wood (12.7\%). The purpose of this study was "to know the effect of adding glass waste powder and bamboo leaf ash on the performance of paving blocks". The data needed in this study are primary data and secondary data. The technique used to collect primary data in this research is the experimental method. The data to be analyzed was obtained from the results of testing in the laboratory using 45 samples. Data were analyzed using multiple linear regression test. All analysis using SPSS software which is then presented in the form of tables, pictures and descriptions. The results showed that the average compressive strength of paving blocks was $B$ quality with regression equation $Y=19.010+(-0.119) X 1+(0.063) X 2$, while for absorption was $D$ quality with regression equation $Y=10.598+(-0.094) X 1+(-0.001)$ $X 2$. In general, the addition of glass waste and bamboo leaf ash has an effect on the compressive strength and water absorption of paving blocks.
\end{abstract}

Keywords: glass waste, bamboo leaf ash waste, paving block 


\begin{abstract}
ABSTRAK
Kaca merupakan salah satu benda yang tidak bisa dilepaskan dari kehidupan manusia. Berdasarkan data Menteri Lingkungan dan Kehutanan (LHK) tahun 2020 menyebutkan bahwa data sampah di Indonesia mencapai 67.8 juta ton, dari jumlah tersebut 0.7 juta ton merupakan sampah kaca. Diketahui jenis sampah yang dihasilkan di Indonesia adalah sampah organik (60\%), sampah plastik (14\%), sampah kertas (9\%), metal (4.3\%), kaca dan kayu (12.7\%). Tujuan penelitian ini "Mengetahui pengaruh penambahan serbuk limbah kaca dan abu daun bambu terhadap kinerja paving block". Data yang dibutuhkan dalam penelitian ini adalah data primer dan data sekunder. Teknik yang digunakan untuk mengumpulkan data primer dalam penelitian ini adalah metode eksperimental. Data yang akan dianalisis diperoleh dari hasil pengujian di laboratorium dengan menggunakan 45 sampel. Data dianalisis dengan menggunakan uji Regresi Linier berganda. Semua analisis menggunakan software SPSS yang kemudian di sajikan dalam bentuk tabel, gambar dan deskripsi. Hasil penelitian menunjukan rata-rata mutu kuat tekan paving block adalah mutu $B$ dengan persamaan regresi $Y=19.010+(-0.119) X 1+$ (0.063) X2, sedangkan untuk penyerapan adalah mutu $D$ dengan persamaan regresi $Y=$ $10.598+(-0.094) X 1+(-0.001) X 2$. Secara general, penambahan limbah kaca dan abu daun bambu memberikan pengaruh terhadap kuat tekan dan penyerapan air paving block.
\end{abstract}

Kata kunci: limbah kaca, limbah abu daun bambu, paving block 


\section{PENDAHULUAN}

Kaca merupakan salah satu benda yang tidak bias dilepaskan dari kehidupan manusia seperti piring, gelas, lampu dan jendela yang ada disekitar kita. Hamper sebagian besar benda-benda tersebut terbuat dari kaca. Adanya limbah kaca yang ditemukan dalam bentuk pecahan botol kaca, piring kaca, gelas kaca pecahan kaca selembaran, dan sebagainya. Berdasarkan data Mentri Lingkungan dan Kehutanan (LHK) tahun 2020 menyebutkan bahwa data sampah di Indonesia mencapai 67.8 juta ton, dari jumlah tersebut 0.7 juta ton merupakan sampah kaca. Dari riset diatas, diketahui jenis sampah yang dihasilkan di Indonesia adalah sampah organik (60\%), sampah plastik (14\%), sampah kertas (9\%), metal $(4.3 \%)$, kaca dan kayu (12.7\%).

Pemanfaatan limbah serbuk kaca dalam penelitian ini adalah limbah serbuk kaca akan dimanfaatkan untuk bahan pengganti sebagian semen. Semen merupakan bahan utama dalam pembuatan paving block dimana penggunaanya juga di butuhkan dalam pelaksanaan konstruksi.

Penggunaan limbah serbuk kaca dalam pengganti sebagian semen diharapkan mampu menjadi alternatif dari berbagai permasalahan dalam dunia konstruksi dan lingkungan. Beberapa hal yang menjadi pertimbangan adalah unsurunsur kimia yang terkandung pada kaca. Apabila kaca dihancurkan menjadi serbuk berkemungkinan berfungsi sebagai filler karena persentase kandungan silika ( $\mathrm{SiO} 2)$, $\mathrm{Na} 2 \mathrm{O}$ dan $\mathrm{CaO}$ pada kaca yang cukup besar yaitu lebih dari 70\% (Karwur, 2013).

Dalam penelitian ini, abu daun bambu juga dijadikan bahan tambah sebagai pengganti sebagian semen. Abu daun bambu jika melalui pembakaran selama 2 jam, diketahui mengandung silika $75.9 \%$ (Safri, 2019). Indonesia merupakan salah satu negara yang memiliki biodiversitas yang tinggi. Tak heran jika sekitar 159 spesies dari total 1250 spesies bambu di dunia bertengger dengan subur di wilayah Indonesia. 88 spesies dari 159 spesies yang ada di Indonesia merupakan spesies endemik Indonesia, sehingga produksi dalam jumlah massal sangat mungkin dilakukan.

Berbagai penelitian telah dilakukan dalam memanfaatkan limbah serbuk kaca sebagai pengganti sebagian semen, diantaranya yang dilakukan oleh Islam, Rahman, \& Kazi (2017) dengan judul "Waste glass powder as partial replacement of cement for sustainable concrete practice”. Penelitian ini menyelidiki studi tentang penggantian sebagian semen dengan serbuk kaca 
sebesar $0-25 \%$ dan super plasticizing sebesar $1 \%$ dari berat semen. Hasil pengujian menunjukan bahwa mortar kaca dan Paving Block daur ulang memberikan kekuatan yang lebih baik dibandingkan sampel kontrol. Pengganti 20\% dari semen dengan kaca bekas dianggap meyakinkan jika dilihat dari segi biaya dan lingkungan.

Khan, Saha, \& Sarker (2019) dengan judul "Reuse of waste glass as a supplementary binder and aggregate for sustainable cement based construction materials: A review". Penelitian ini menyelidiki studi tentang penggantian sebagian semen dengan limbah serbuk kaca. Hasil penelitian menunjukan Penggunaan serbuk kaca meningkat secara signifikan berdasarkan sifat mekanik dan ketahanan mortar semen dan Paving Block bila ukuran partikelnya bubuk kaca kurang dari $45 \mu \mathrm{m}$ dan tingkat penggantian semen sekitar 10-40\%. Penelitian ini juga mengamati bahwa agregat halus kaca dapat digunakan hingga 100\% dari agregat halus dalam mortar dan paving block tanpa efek negatif pada sifat mekanik dan daya tahan saat itu ukuran partikel kurang dari $1 \mathrm{~mm}$.

Aliabdo \& M. Elmoaty (2016) dengan judul "Utilization of waste glass powder in the production of cement and concrete". Penelitian ini menyelidiki studi tentang penggantian sebagian semen dengan limbah serbuk kaca. Variasi limbah serbuk kaca yang digunakan yaitu $0.0 \%$, $5.0 \%, 10.0 \%, 15.0 \%, 20.0 \%$ dan $25.0 \%$ menurut berat semen. Hasil pengujian menunjukkan bahwa kaca serbuk memiliki karakteristik pozzolan dan penggunaan serbuk kaca tidak berpengaruh nyata terhadap waktu pengerasan dan ekspansi semen. Kuat tekan paving block, kuat tarik, absorpsi, rasio void dan densitas ditingkatkan sebagai hasil dari penggunaan $10.0 \%$ pengganti semen bubuk kaca. Penggunaan serbuk kaca lebih dari $15.0 \%$ sebagai pengganti semen menurunkan kuat tekan Paving Block 28 hari. Pengurangan rasio w/c diperlukan untuk membatalkan pengurangan kuat tekan paving block. Untuk campuran paving block $45 \mathrm{Mpa}$ cukup untuk mengurangi ransum semen air sekitar 0.03 sampai hilangkan efek negatif penggunaan bubuk kaca $15 \%$ sebagai semen penggantian.

Penelitian yang memanfaatkan abu daun bambu sebagai pengganti sebagian semen diantaranya Diana, Fansuri, \& Deshariyanto (2020) dengan judul "Penambahan Abu Daun Bambu Sebagai Substitusi Material Semen Terhadap Kinerja Paving Block". Penelitian ini menyelidiki studi tentang penggantian sebagian semen dengan abu daun bambu. Variasi yang digunakan adalah 0\%, 3\%, 
5\%, dan 7\%. Hasil menunjukkan nilai kuat tekan yang dipengaruhi oleh variasi campuran abu daun bambu adalah $\mathrm{Y}=$ $13.871+0.419 \mathrm{X}$ dimana $\mathrm{X}$ adalah variasi campuran dan y adalah nilai kuat tekan Paving Block. Nilai t-hitung $=2.504>\mathrm{t}-$ tabel $=1.812$ mengindikasikan ada pengaruh yang signifikan antara penambahan variasi campuran abu daun bambu terhadap kuat tekan. Variasi optimum terdapat pada proporsi campuran abu daun bambu $5 \%$ dan $7 \%$.

Berdasarkan pembahasan dari latar belakang diatas, penelitian ini memfokuskan untuk meneliti lebih lanjut tentang penambahan serbuk limbah kaca dan abu daun bambu terhadap kinerja paving block.

Adapun rumusan masalah dalam penelitian ini yang akan diselesaikan sesuai kurun waktu yang telah ditentukan secara umum adalah "Bagaimana pengaruh Penambahan Serbuk Limbah Kaca Dan Abu Daun Bambu Terhadap Kinerja Paving Block”.

\section{KAJIAN PUSTAKA}

\subsection{Paving Block}

Paving block berdasarkan SNI 030691-1996 tentang Bata Beton (Paving Block) adalah suatu komposisi bahan bangunan yang dibuat dari campuran semen Portland atau bahan perekat hidrolis sejenisnya, air dan agregat dengan atau tanpa bahan tambahan lainnya yang tidak mengurangi mutu beton itu.

\subsection{Bahan Penyusun Paving Block}

Kualitas dari Paving Block dapat ditentukan dari berbagai faktor diantaranya dari bahan yang digunakan, proses pembuatan Paving Block, dan perlakuan perawatan Paving Block tersebut. Bahan dasar pembuatan Paving Block yaitu sebagai berikut:

\section{Semen Portland}

Semen portland adalah bahan perekat hidrolis yang dihasilkan dengan cara menghaluskan klinker (bahan ini terutama dari silikat kalsium yang bersifat hidrolis). Semen hidrolis sendiri adalah semen yang dapat bereaksi dengan air dan menghasilkan benda keras yang stabil dan tidak mudah larut (Samekto \& Rahmadiyanto, 2001).

2. Agregat

Agregat merupakan bahan penyusun atau pengisi dalam pembuatan Paving Block atau mortar. Dalam komposisi Paving Block, agregat menempati ruang sekitar $70 \%$ dari berat volume Paving Block. Bahan penyusun 
Paving Block sangat mempengaruhi kualitas Paving Block (Samekto \& Rahmadiyanto, 2001). Sifat utama dalam pengujian agregat yang harus dipertimbangkan adalah kekuatan hancur, ketahanan terhadap benturan (dilakukan dengan menggunakan uji Los Angeles), porositas dan penyerapan air.

\section{Air}

Air merupakan komposisi yang tidak kalah penting diantara komposisi lainnya, karena air berfungsi membasahi komposisi lainnya misalnya semen dan pasir.

\section{Limbah Kaca}

Sisa pecahan kaca atau botol kaca yang dimanfaatkan kembali sebagai material penyusun paving block.

\section{Limbah Daun Bambu}

Sisa daun bambu yang dilakukan pembakaran selama 2 jam kemudian dimanfaatkan sebagai material penyusun paving block.

\subsection{Pembuatan dan Pengujian Paving Block Segar}

1. Pengujian bahan

Pengujian bahan dilakukan untuk mengetahui kualitas agregat yang digunakan yaitu kualitas pasir dan bahan pengikat (semen, abu kaca dan abu daun bambu). Pengujian berat jenis dan penyerapan air agregat halus menggunakan prosedur pada SNI 1970:2008. Pengujian analisis saringan agregat halus dan agregat kasar menggunakan SNI ASTM C136-2012.

\section{Mix Design Paving Block}

Mix desain adalah suatu proses perencanaan perhitungan proporsi campuran material pembuat paving block. Tujuan dari mix desain ini adalah untuk membuat paving block sesuai dengan mutu yang dinginkan. Setiap bangunan membutuhkan kuat tekan yang berbeda - beda oleh sebab itu rekayasa dalam pembuatan paving block sangat bergantung dengan mix desain yang dibuat. Prosedur pembuatan paving block dalam penelitian ini menggunakan SNI 03-0691-1996.

\section{Perawatan (Curing) Paving Block}

Perawatan (Curing) paving block dilakukan untuk mengurangi proses hidrasi paving block selama proses pengikatan antara material penyusun. Perawatan paving block biasanya dilakukan 1x24 jam setelah paving block dicetak. Adapun waktu yang dibutuhkan dalam proses 
perawatan paving block adalah 28 hari. Metode perawatan paving block yang digunakan adalah pembasahan menggunakan air.

4. Uji Kuat Tekan Paving Block Kuat tekan paving block dilakukan pada saat umur paving block mencapai 28 hari. Adapun perhitungan kuat tekan sebagai berikut:

Kuat tekan $=\mathrm{P} / \mathrm{A}$

keterangan:

$\mathrm{P}=$ Beban tekan $(\mathrm{N})$

$\mathrm{A}=$ Luas bidang tekan $\left(\mathrm{mm}^{2}\right)$

\subsection{Penelitian Terdahulu}

Adapun beberapa penelitian terdahulu yang dijadikan dasar acuan dalam penelitian kali ini, diantaranya:

1. Penelitian yang pernah dilakukan oleh Islam, Rahman, \& Kazi (2017) dengan judul Waste glass powder as partial replacement of cement for sustainable concrete practice. Jutaan ton limbah kaca dihasilkan setiap tahun di seluruh dunia. Setelah kaca menjadi limbah, kaca tersebut akan dibuang sebagai tempat pembuangan sampah, yang tidak berkelanjutan karena tidak terurai di lingkungan. Kaca pada prinsipnya terdiri dari silika. Penggunaan giling (tanah) Limbah kaca dalam beton sebagai pengganti sebagian semen bisa menjadi langkah penting menuju pembangunan berkelanjutan (berwawasan lingkungan ramah, hemat energi dan ekonomis) sistem infrastruktur. Ketika kaca limbah digiling menjadi partikel berukuran mikro, diharapkan bisa mengalami reaksi pozzolanic dengan semen hidrat, membentuk Kalsium Silikat Hidrat sekunder $(\mathrm{C}-\mathrm{S}-\mathrm{H})$. Dalam kimia penelitian ini sifat kaca bening dan berwarna dievaluasi. Analisis kimia sampel gelas dan semen ditentukan dengan menggunakan Xray fluoresensi (XRF) dan menemukan perbedaan kecil dalam komposisi antara kaca bening dan berwarna. Aliran dan tekan Uji kekuatan mortar dan beton dilakukan dengan penambahan 0-25\% ground glass dengan perbandingan air terhadap bahan pengikat (semen + kaca). Tetap sama untuk 
semua level penggantian.

Dengan penambahan kaca, aliran mortar sedikit meningkat sementara efeknya kecil pada beton kemampuan kerja dicatat. Untuk mengevaluasi efek pengepakan dan pozzolan, tes lebih lanjut juga dilakukan dengan detail campuran yang sama dan Dosis admixture pemlastisisasi super $1 \%$ (menurut berat semen) dan umumnya ditemukan peningkatan kuat tekan mortar dengan campuran. Seperti pada mortar, sampel kubus beton disiapkan dan diuji kekuatannya (hingga pengeringan 1 tahun). Hasil pengujian kekuatan tekan menunjukkan bahwa mortar kaca dan beton daur ulang memberikan kekuatan yang lebih baik dibandingkan sampel kontrol. Pengganti 20\% dari semen dengan kaca bekas dianggap meyakinkan mengingat biaya dan lingkungan.

2. Penelitian yang pernah dilakukan oleh Harrison, Berenjian, \& Seifan (2020) dengan judul "Recycling of waste glass as aggregate in cement-based materials". Kaca adalah bahan yang biasa dibuat dari sumber daya alam seperti pasir. Meski banyak dari limbah kaca didaur ulang untuk membuat produk kaca baru, sebagian besar masih dikirim ke TPA. Gelas itu berguna sumber daya yang tidak dapat terurai secara hayati, menempati ruang TPA yang berharga. Untuk mengatasi limbah kaca yang ada menuju TPA, bentuk daur ulang alternatif perlu diselidiki. Industri konstruksi adalah salah satunya penghasil emisi $\mathrm{CO} 2$ terbesar di dunia, menghasilkan hingga $8 \%$ dari $\mathrm{CO} 2$ global untuk memproduksi semen. Menggunakan pasir sebagian besar menghabiskan sumber daya alam untuk pembuatan mortir atau beton. Review ini mengeksplorasi kemungkinan memasukkan limbah kaca ke dalam bahan berbasis semen. Ditemukan limbah kaca tersebut tidak cocok sebagai pengganti bahan baku untuk menghasilkan klinker dan sebagai agregat kasar, karena bersifat cair 
keadaan diproduksi di kiln dan luas permukaan halus, masingmasing. Hasil yang menjanjikan ditemukan saat memasukkan partikel kaca halus dalam bahan berbasis semen karena pozzolanic yang menguntungkan reaksi yang menguntungkan sifat mekanik. Ditemukan bahwa $20 \%$ semen dapat diganti kaca limbah $20 \mathrm{~mm}$ tanpa efek merugikan pada sifat mekanik. Penggantian lebih tinggi dari $30 \%$ dapat menyebabkan dampak negatif karena jumlah $\mathrm{CaCO} 3$ yang tersisa tidak mencukupi untuk bereaksi dengan silika dari gelas, yang dikenal sebagai efek pengenceran. Sebagai pengganti agregat halus untuk kaca limbah meningkat lebih dari 20\%, sifat mekanik menurun secara proporsional; namun, hingga $20 \%$ memiliki hasil yang serupa dengan bercampur secara tradisional.

3. Penelitian yang pernah dilakukan oleh Du \& Tan (2014) dengan judul "Waste Glass Powder as Cement Replacement in Concrete". Reaktivitas pozzolan dari bubuk kaca limbah dipelajari secara eksperimental pada tingkat penggantian semen $0,15,30,45$ dan $60 \%$ berat. Hasil penelitian menunjukkan bahwa kuat tekan beton tidak berkurang dengan adanya substitusi semen setelah 28 hari karena reaksi pozzolan antara bubuk kaca dan produk hidrasi semen, jika penggantian di bawah $30 \%$. Juga, ketahanan terhadap ion klorida dan penetrasi air terus meningkat seiring dengan peningkatan isi bubuk kaca hingga 60\% pengganti semen. Pada tingkat penggantian $60 \%$, resistivitas listrik dan kedalaman penetrasi air berkurang masing-masing sebesar $95 \%$ dan $80 \%$, sedangkan kuat tekan dipertahankan sebagai $85 \%$. Peningkatan dalam sifat daya tahan ini disebabkan oleh mikrostruktur yang disempurnakan, terutama di antarmuka zona transisi. Distribusi ukuran pori diukur untuk mengkonfirmasi kehalusan pori-pori kapiler yang sebagian memblokir jalur air dan 
ion klorida. Studi ini juga

menunjukkan bahwa beton

kinerja tinggi (ditingkatkan

kekuatan dan impermeabilitas

terhadap klorida dan air) dapat

dicapai dengan menggunakan

bubuk kaca sebagai aditif $15 \%$,

yang berkontribusi pada reaksi pozzolan bukannya denda inert untuk kemasan kompak.

\section{METODE PENELITIAN}

\subsection{Tahapan Penelitian}

Adapun tahapan pelaksanaan penelitian dapat dilihat berdasarkan diagram alur seperti pada Gambar 1.

Data Mentri Lingkungan dan Kehutanan (LHK) tahun 2020 menyebutkan bahwa data sampah di Indonesia mencapai 67.8 juta ton, dari jumlah tersebut 0.7 juta ton merupakan sampah kaca. Indonesia merupakan salah satu negara yang memiliki biodiversitas yang tinggi. Tak heran jika sekitar 159 spesies dari total 1250 spesies bambu di dunia bertengger dengan subur di wilayah Indonesia. Dengan melakukan pemanasan selama 2 jam, abu daun bambu dapat dimanfaatkan sebagai bahan pengikat material konstruksi. Sehingga, Butuh inovasi untuk merubah limbah kaca dan sampah abu daun bambu menjadi bahan material konstruksi.

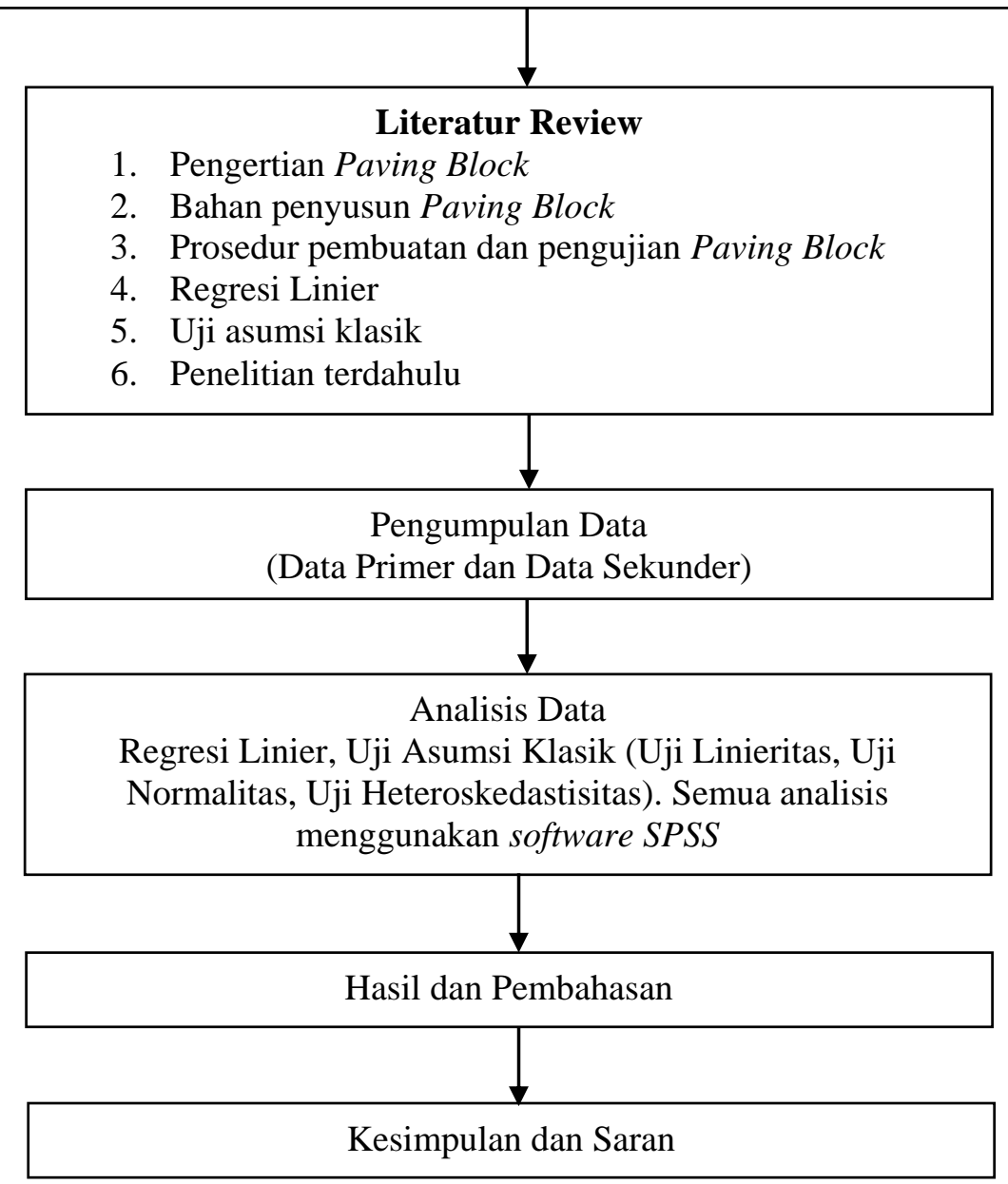

Gambar 1. Flowchart Penelitian 


\subsection{Model Yang Digunakan}

Model yang digunakan dalam penelitian ini adalah Paving Block dengan campuran limbah kaca (dijadikan serbuk sehingga memiliki gradasi seperti semen) dan limbah daun bambu (melalui proses pembakaran selama 2 jam, kemudian dilakukan grading agar memiliki tingkat kesamaan dengan semen). Adapun sampel yang digunakan dalam penelitian ini berjumlah 5 buah benda uji paving block. Tabel 2 menunjukkan rincian benda uji untuk masing-masing variasi gradasi plastik.

\section{Tabel 1. Jumlah Total Benda Uji}

\begin{tabular}{ccc}
\hline $\begin{array}{c}\text { Variasi Serbuk } \\
\text { Limbah Kaca (\%) }\end{array}$ & $\begin{array}{c}\text { Variasi Abu Daun } \\
\text { Bambu (\%) }\end{array}$ & $\begin{array}{c}\text { Jumlah } \\
\text { Benda Uji }\end{array}$ \\
\hline 0 & 0 & 5 \\
0 & 5 & 5 \\
0 & 7 & 5 \\
10 & 0 & 5 \\
10 & 5 & 5 \\
10 & 7 & 5 \\
20 & 0 & 5 \\
20 & 5 & 5 \\
20 & 7 & 5 \\
\multicolumn{2}{c}{ Total Benda Uji }
\end{tabular}

\subsection{Teknik Pengumpulan Data}

Data yang dibutuhkan dalam penelitian ini adalah data primer dan data sekunder. Teknik yang digunakan untuk mengumpulkan data primer dalam penelitian ini adalah metode eksperimental. Dalam hal ini peneliti melakukan uji laboratorium yaitu:
1. Pengujian bahan agregat diantaranya pengujian semen: berat jenis semen, waktu mengikat dan mengeras semen, berat volume semen. Pengujian agregat halus: analisa saringan agregat halus, kadar air pasir, berat jenis pasir, berat volume pasir, tes kebersihan pasir terhadap lumpur.

2. Pembuatan paving block dimulai dengan perhitungan mix design, pencetakan paving block dengan menggunakan mesin pres, perawatan paving block.

3. Pengujian kuat tekan paving block dengan menggunakan compression machine.

Pengumpulan data sekunder dalam penelitian ini dilakukan dengan menggunakan literatur review.

\subsection{Teknik Analisis Data}

Data yang akan dianalisis diperoleh dari hasil pengujian di laboratorium. Data dianalisis dengan menggunakan uji Regresi Linier berganda, Uji Asumsi Klasik (Uji Linieritas, Uji Normalitas, Uji Heteroskedastisitas). Semua analisis menggunakan software SPSS yang kemudian di sajikan dalam bentuk tabel, gambar dan deskripsi. 
4 HASIL DAN PEMBAHASAN

\subsection{Bahan Yang Digunakan}

Adapun bahan-bahan yang

digunakan dalam pelaksanaan penelitian ini adalah air, semen, limbah serbuk kaca, dan limbah daun bambu. Berikut ini gambaran bahan yang digunakan,

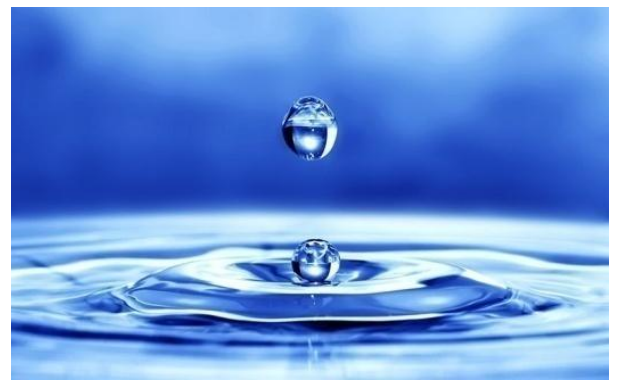

(a) Air

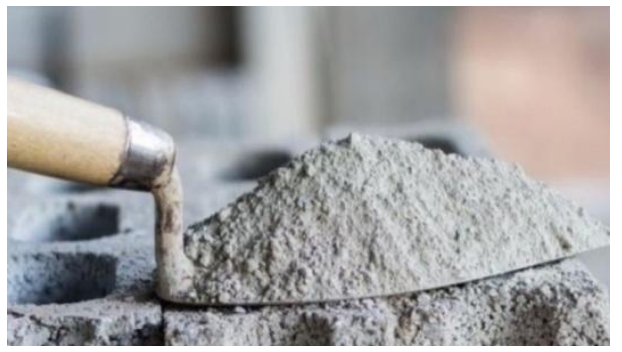

(c) Semen

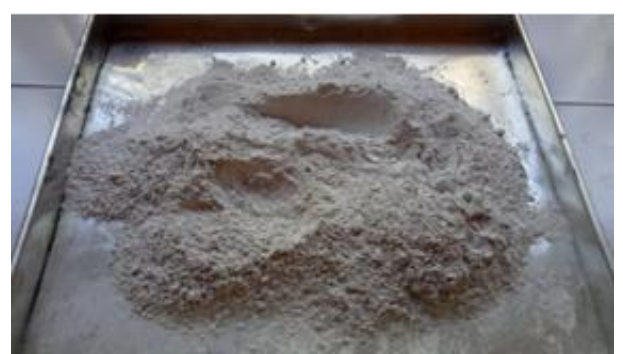

(e) Limbah serbuk kaca

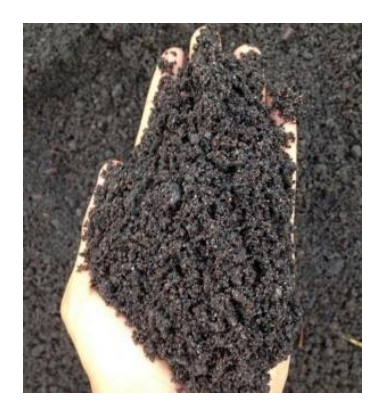

(b) Pasir

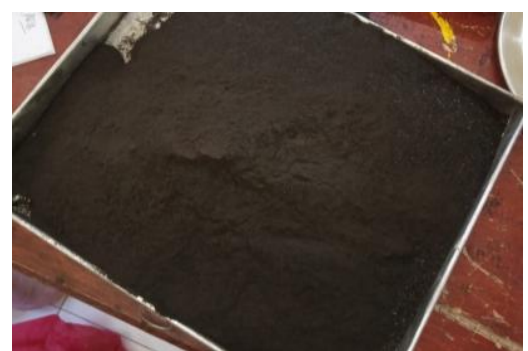

(d) Limbah abu daun bambu

Gambar 2. Bahan-Bahan Penelitian

\subsection{Pengujian Paving Block}

Pengujian berdasar syarat mutu paving block sesuai persyaratan SNI 030691-1996, yaitu diperoleh hasil sebagai berikut:

1. Pengujian Sifat Tampak

Dalam penelitian ini benda uji paving block yang dihasilkan terdapat beberapa tinggi permukaan yang tidak rata, retak-retak dan cacat bagian sudutnya.Hal ini dikarenakan oleh faktor kurangnya kontrol pemadatan pada saat pelaksanaan pembuatan paving block. 


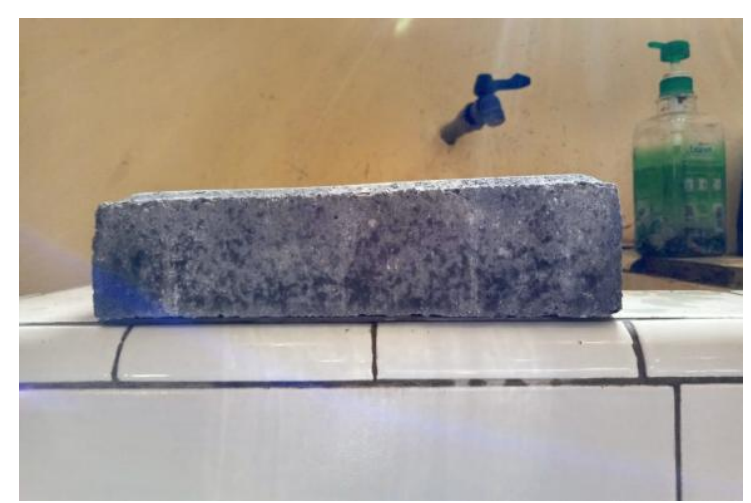

Gambar 3. Tinggi Paving Block Tidak Rata

2. Pengujian Ukuran

Pengukuran ketebalan paving block dengan penggaris dilakukan terhadap tiga tempat yang berbeda dan diambil nilai rata-rata.Dari data ketebalan paving block disetiap perlakuan, maka sampel dipilih yang memiliki nilai tebal paling baik sesuai persyaratan ukuran tebal nominal minimum $60 \mathrm{~mm}$ dengan toleransi $\pm 8 \%(60 \mathrm{~mm}+8 \%=64.8$ $\approx 65 \mathrm{~mm}$ ) untuk pengujian kuat tekan dan sampel yang memiliki nilai tebal kurang baik sesuai persyaratan ukuran tebal nominal minimum $60 \mathrm{~mm}$ dengan toleransi \pm
$8 \%(60 \mathrm{~mm}-8 \%=55.2 \approx 55 \mathrm{~mm})$ untuk pengujian penyerapan.

3. Pengujian Sifat Fisika Kuat Tekan Paving Block

Rumus perhitungan kuat tekan dapat dihitung berdasarkan SNI 0306919-1996 dan British Standard 6717-1:1993 dengan menggunakan faktor ketebalan 1.06 untuk paving block. Sampel yang digunakan untuk pengujian kuat tekan sebanyak 3 buah benda. Tabel 2 merupakan hasil pengujian kuat tekan paving block.

4. Pengujian Sifat Fisika Serapan Air Paving Block

Rumus perhitungan penyerapan air berdasarkan SNI-03-0691-1996. Sampel yang digunakan untuk pengujian penyerapan air sebanyak 2 buah benda uji pada setiap perlakuan. Tabel 2 merupakan hasil pengujian penyerapan air paving block.

Tabel 2. Data Rekapitulasi Variasi Terhadap Kuat Tekan dan Penyerapan Paving Block

\begin{tabular}{cccc}
\hline \multicolumn{2}{c}{ Variasi } & \multirow{2}{*}{ Kuat Tekan $\left(\mathrm{N} / \mathrm{mm}^{2}\right)$} & \multirow{2}{*}{ Penyerapan $(\%)$} \\
\hline Serbuk Kaca (\%) & Abu Daun Bambu (\%) & 20.030 & 11.791 \\
0 & 0 & 18.027 & 9.841 \\
0 & 5 & 18.107 & 9.772 \\
10 & 7 & 18.989 & 9.549 \\
10 & 0 & 18.187 & 9.175 \\
10 & 5 & 20.271 & 10.992 \\
20 & 7 & 14.582 & 7.912 \\
20 & 0 & 16.104 & 8.942 \\
20 & 5 & 16.745 & 8.898 \\
\hline
\end{tabular}




\subsection{Mutu Paving Block}

Hasil penelitian ini menunjukkan klasifikasi paving block pada masingmasing perlakuan sebagai berikut:

1. Ditinjau Dari Kuat Tekan

a. Variasi $0 \%$ serbuk kaca $0 \%$ abu daun bambu dengan hasil kuat tekan 20.030 $\mathrm{N} / \mathrm{mm}^{2}$ melebihi syarat klasifikasi bata beton mutu B ditinjau dari kuat tekan rata-rata maksimum standar $20 \mathrm{MPa}$ dan kuat tekan minimum standar $17.0 \mathrm{MPa}$ yang dapat digunakan untuk peralatan parkir.

b. Variasi $0 \%$ serbuk kaca $5 \%$ abu daun bambu dengan hasil kuat tekan 18.027 $\mathrm{N} / \mathrm{mm}^{2}$ termasuk klasifikasi bata beton mendekati mutu B ditinjau dari kuat tekan rata-rata mendekati $20 \mathrm{MPa}$ dan kuat tekan minimum memenuhi standart 17.0 MPa yang dapat digunakan untuk pejalan kaki.

c. Variasi $0 \%$ serbuk kaca $7 \%$ abu daun bambu dengan hasil kuat tekan 18.107 $\mathrm{N} / \mathrm{mm}^{2}$ termasuk klasifikasi bata beton mendekati mutu
B ditinjau dari kuat tekan rata-rata mendekati $20 \mathrm{MPa}$ dan kuat tekan minimum memenuhi standart 17.0 MPa yang dapat digunakan untuk pelataran parker.

d. Variasi $10 \%$ serbuk kaca $0 \%$ abu daun bambu dengan hasil kuat tekan 18.989 $\mathrm{N} / \mathrm{mm}^{2}$ termasuk klasifikasi bata beton mendekati mutu B ditinjau dari kuat tekan rata-rata mendekati $20 \mathrm{MPa}$ dan kuat tekan minimum memenuhi standart 17.0 MPa yang dapat digunakan untuk pejalan kaki.

e. Variasi $10 \%$ serbuk kaca $5 \%$ abu daun bambu dengan hasil kuat tekan 18.187 $\mathrm{N} / \mathrm{mm}^{2}$ termasuk klasifikasi bata beton mendekati mutu B ditinjau dari kuat tekan rata-rata mendekati $20 \mathrm{MPa}$ dan kuat tekan minimum memenuhi standart 17.0 MPa yang dapat digunakan untuk pejalan kaki.

f. Variasi $10 \%$ serbuk kaca $7 \%$ abu daun bambu dengan hasil kuat tekan 20.271 $\mathrm{N} / \mathrm{mm}^{2}$ melebihi syarat 
klasifikasi bata beton mutu

Bditinjau dari kuat tekan

rata-rata maksimum standar

$20 \mathrm{MPa}$ dan kuat tekan

minimum standar 17.0 MPa

yang dapat digunakan untuk

peralatan parkir.

g. Variasi $10 \%$ serbuk kaca $7 \%$ abu daun bambu dengan hasil kuat tekan 14.582 $\mathrm{N} / \mathrm{mm}^{2}$ termasuk klasifikasi bata beton mendekati mutu Cditinjau dari kuat tekan rata-rata mendekati $15 \mathrm{MPa}$ dan kuat tekan minimum memenuhi standart 12.5 MPa yang dapat digunakan untuk pelataran parkir.

h. Variasi $20 \%$ serbuk kaca $5 \%$ abu daun bambu dengan hasil kuat tekan 16.104 $\mathrm{N} / \mathrm{mm}^{2}$ melebihi syarat klasifikasi bata beton mutu C ditinjau dari kuat tekan rata-rata maksimum standar $15 \mathrm{MPa}$ dan kuat tekan minimum standar $12.5 \mathrm{MPa}$ yang dapat digunakan untuk peralatan parkir.

i. Variasi $20 \%$ serbuk kaca $7 \%$ abu daun bambu dengan hasil kuat tekan 16.745
$\mathrm{N} / \mathrm{mm}^{2}$ melebihi syarat klasifikasi bata beton mutu Cditinjau dari kuat tekan rata-rata maksimum standar $15 \mathrm{MPa}$ dan kuat tekan minimum standar $12.5 \mathrm{MPa}$ yang dapat digunakan untuk peralatan parkir.

2. Ditinjau Dari Penyerapan Air

a. Variasi $0 \%$ serbuk kaca $0 \%$ abu daun bambu dengan hasil penyerapan rata-rata $11.791 \%$ belum memenuhi syarat kasifikasi mutu paving block dengan penyerapan air rata-rata maksimum 10\% (mutu D).

b. Variasi $0 \%$ serbuk kaca $5 \%$ abu daun bambu dengan hasil penyerapan rata-rata $9.841 \%$ memenuhi syarat kasifikasi mutu paving block dengan penyerapan air rata-rata maksimum $10 \%$ (mutu D).

c. Variasi $0 \%$ serbuk kaca $7 \%$ abu daun bambu dengan hasil penyerapan rata-rata $9.772 \%$ memenuhi syarat kasifikasi mutu paving block dengan penyerapan 
air rata-rata maksimum $10 \%$ (mutu D).

d. Variasi $10 \%$ serbuk kaca $0 \%$ abu daun bambu dengan hasil penyerapan rata-rata 9.549\% memenuhi syarat kasifikasi mutu paving block dengan penyerapan air rata-rata maksimum $10 \%$ (mutu D).

e. Variasi $10 \%$ serbuk kaca $5 \%$ abu daun bambu dengan hasil penyerapan rata-rata $9.175 \%$ memenuhi syarat kasifikasi mutu paving block dengan penyerapan air rata-rata maksimum $10 \%$ (mutu D).

f. Variasi $20 \%$ serbuk kaca $0 \%$ abu daun bambu dengan hasil penyerapan rata-rata $7.912 \%$ belum memenuhi syarat kasifikasi mutu paving block dengan penyerapan air rata-rata maksimum 10\% (mutu B).

g. Variasi $20 \%$ serbuk kaca $5 \%$ abu daun bambu dengan hasil penyerapan rata-rata $9.175 \%$ memenuhi syarat kasifikasi mutu paving block dengan penyerapan air rata-rata maksimum $10 \%$ (mutu D).

h. Variasi $20 \%$ serbuk kaca $7 \%$ abu daun bambu dengan hasil penyerapan rata-rata $8.898 \%$ memenuhi syarat kasifikasi mutu paving block dengan penyerapan air rata-rata maksimum $10 \%$ (mutu D).

i. Variasi $10 \%$ serbuk kaca $5 \%$ abu daun bambu dengan hasil penyerapan rata-rata $9.175 \%$ memenuhi syarat kasifikasi mutu paving block dengan penyerapan air rata-rata maksimum $10 \%$ (mutu D).

\subsection{Analisis Regresi Linier Berganda}

Analisis regresi dilakukan dengan bantuan aplikasi SPSS. Analisis regresi dilakukan terhadap kuat tekan dan penyerapan paving block.

Model persamaan regresi berganda untuk memperkirakan nilai kuat tekan yang dipengaruhi oleh limbah serbuk kaca dan abu daun bambua dalah $\mathrm{Y}=19.010+$ $(-0.119) \mathrm{X} 1+(0.063) \mathrm{X} 2$.

Y adalah Kuat Tekan, X1 adalah Variasi Limbah Serbuk Kaca, X2 adalah Variasi Abu Daun Bambu. 
Hipotesis berdasarkan teknik nilai $\alpha$-nya dibagi 2, sehingga nilai $\alpha=$ probabilitas. Dari Tabel 3 coefficient $(\alpha)$ $0.05 / 2=0.025$. Berdasar tabel coefficients dapat dianalisis ada atau tidaknya pada limbah serbuk diperoleh nilai Sig $=$ pengaruh variasi limbah serbuk kaca $0.123>0.025$ (Ho diterima). Dengan secara parsialterhadap nilai kuat tekan.Kriteria pengujian jika Sig $\leq$ a (Ho ditolak), dan jika $\mathrm{Sig} \geq \mathrm{a}$ (Ho diterima). Untuk nilai $\alpha$, karena uji dua sisi maka demikian dapat diambil keputusan bahwa tidak ada pengaruh yang signifikan antara penambahan variasi limbah serbuk kacaterhadap nilai kuat tekan paving block.

Tabel 3. Coefficient (a) Analisis Regresi Linier Berganda Kuat Tekan

\begin{tabular}{|c|c|c|c|c|c|c|}
\hline & \multirow[t]{2}{*}{ Model } & \multicolumn{2}{|c|}{ Unstandardized Coefficients } & \multirow{2}{*}{$\begin{array}{c}\text { Standardized } \\
\text { Coefficients } \\
\text { Beta }\end{array}$} & \multirow[t]{2}{*}{$\mathrm{T}$} & \multirow[t]{2}{*}{ Sig. } \\
\hline & & B & Std. Error & & & \\
\hline \multirow{3}{*}{1} & (Constant) & 19.010 & 1.265 & & 15.026 & .000 \\
\hline & Serbuk Kaca & -.119 & .074 & -.310 & -1.599 & .123 \\
\hline & Abu Daun Bambu & .063 & .206 & .059 & .304 & .764 \\
\hline & ependent Variable: & Tekan & & & & \\
\hline
\end{tabular}

Tabel 4. Coefficient ( $\alpha$ ) Analisis Regresi Linier Berganda Penyerapan

\begin{tabular}{|c|c|c|c|c|c|c|}
\hline & \multirow[t]{2}{*}{ Model } & \multicolumn{2}{|c|}{ Unstandardized Coefficients } & \multirow{2}{*}{$\begin{array}{c}\text { Standardized } \\
\text { Coefficients } \\
\text { Beta } \\
\end{array}$} & \multirow[t]{2}{*}{$\mathrm{T}$} & \multirow[t]{2}{*}{ Sig. } \\
\hline & & $\mathrm{B}$ & Std. Error & & & \\
\hline \multirow{3}{*}{1} & (Constant) & 10.598 & .679 & & 15.598 & .000 \\
\hline & Serbuk Kaca & -.094 & .040 & -.520 & -2.360 & .032 \\
\hline & $\begin{array}{l}\text { Abu Daun Bambu } \\
\text { ependent Variable: } \mathrm{F}\end{array}$ & rapan & .111 & -.002 & -.007 & .994 \\
\hline
\end{tabular}

Model persamaan regresi berganda untuk memperkirakan nilai penyerapan yang dipengaruhi oleh limbah serbuk kaca dan abu daun bambu adalah $\mathrm{Y}=10.598+$ $(-0.094) \mathrm{X} 1+(-0.001) \mathrm{X} 2$. Y adalah Kuat Tekan, X1 adalah Variasi Limbah Serbuk Kaca, X2 adalah Variasi Abu Daun Bambu.

Dari Tabel 4 coefficient $(\alpha)$ dapat dianalisis ada atau tidaknya pengaruh variasi abu daun bambu secara parsial terhadap nilai penyerapan. Kriteria pengujian jika Sig $\leq$ a (Ho ditolak), dan jika $\mathrm{Sig} \geq \mathrm{a}$ (Ho diterima). Untuk nilai $\alpha$, karena uji dua sisi maka nilai $\alpha$-nya dibagi 2, sehingga nilai $\alpha=0.05 / 2=0.025$. Berdasar tabel coefficients pada abu daun bambu diperoleh nilai Sig $=0.994>0.025$ (Ho diterima). Dengan demikian dapat diambil keputusan bahwa tidak ada pengaruh yang signifikan antara penambahan variasi abu daun bambu terhadap nilai penyerapan paving block. 


\section{SIMPULAN}

Dalam penelitian ini pemanfaatan serbuk kaca dan abu daun bambu sebagai bahan subsitusi semen pada paving block menghasilkan kuat tekan rata-rata mutu tinggi standar SNI 03-0691-1996 dengan hasil penyerapan air rata-rata paving block hampir semua variasi memenuhi persyaratan dari standar SNI 03-0691-1996 mutu D (10\%). Dimana kuat tekan ratarata maksimum paving block terjadi pada penambahan variasi $10 \%$ serbuk kaca dan $7 \%$ abu daun bambu dari volume semen yaitu sebesar $20.271 \mathrm{~N} / \mathrm{mm}^{2}$ melebihi mutu B ditinjau dari kuat tekan maksimum $20 \mathrm{MPa}$ dan kuat tekan minimum standar 17.0 MPa yang dapat digunakan untuk peralatan parkir, dengan penyerapan air rata-rata belum memenuhi persyaratan SNI mutu D (10\%) yaitu sebesar 10.992\% yang dapat digunakan untuk pejalan kaki.

Penelitian menunjukan rata-rata mutu kuat tekan paving block adalah mutu B dengan persamaan regresi $\mathrm{Y}=19.010+$ $(-0.119) \mathrm{X} 1+(0.063) \mathrm{X} 2$, sedangkan untuk penyerapan adalah mutu $\mathrm{D}$ dengan persamaan regresi $\mathrm{Y}=10.598+(-0.094)$ $\mathrm{X} 1+(-0.001) \mathrm{X} 2$. Secara general, penambahan limbah kaca dan abu daun bambu memberikan pengaruh terhadap kuat tekan dan penyerapan air paving block.

\section{DAFTAR PUSTAKA}

Aliabdo, A. A., \& M. Elmoaty, A. (2016). Utilization of Waste Glass Powder in The Production of Cement and Concrete. Construction and Building Materials, 124, 866-877.

Anonim. (1996). SNI 03-0691-1996 tentang Bata Beton (Paving Block). Jakarta: Badan Standarisasi Nasional.

Anonim. (2002). Metode Pengambilan Contoh dan Pengujian Abu Terbang atau Pozolan Alam Sebagai Mineral Pencampuran dalam Beton Semen Portland. Jakarta: Badan Standarisasi Nasional.

Anonim. (2004). Semen Portland. Jakarta: Badan Standarisasi Nasional.

Anonim. (2008). SNI 1970 : 2008 tentang Pengujian Berat Jenis dan Penyerapan Air Agregat Halus. Jakarta: Badan Standarisasi Nasional.

Anonim. (2012). SNI ASTM C136 tentang Pengujian Analisa Saringan Agregat Halus dan Agregat Kasar. Bandung: Badan Standarisasi Nasional.

Diana, A. I., Fansuri, S., \& Deshariyanto, D. (2020). Penambahan Abu Daun Bambu Sebagai Substitusi Material Semen Terhadap Kinerja Beton. PADURAKSA, 9 (2), 172-182.

Du, H., \& Tan, K. H. (2014). Waste Glass Powder as Cement Replacement in Concrete. Journal of Advanced Concrete Technology, 12, 468-477.

Harrison, E., Berenjian, A., \& Seifan, M. (2020). Recycling of waste glass as aggregate in cement-based materials. Environmental Science and Ecotechnology, 1-8.

Islam, G. S., Rahman, M., \& Kazi, N. (2017). Wate Glass Powder as Partial Replacement of Cement for 
Sustainable Concrete Practice. International Journal of Sustainable Built Environment, 6, 37-44.

Karwur, H. (2013). Kuat tekan beton dengan bahan tambah serbuk kaca sebagai substitusi parsial semen. Jurnal Sipil Statik, 1 (4).

Khan, M. N., Saha, A., \& Sarker, P. (2019). Reuse of Waste Glass as A Suoplementary Binder and Aggregate for Sustainable Cement Based Construction Materials : A Review. Journal of Building Engineering.

Safri, M. R. (2019). Pengaruh Penggunaan Abu Bambu Sebagai Substitusi Parsial Semen Terhadap Kuat Tekan Beton . Sumenep: Program Studi Teknik Sipil Fakultas Teknik Universitas Wiraraja.

Samekto, W., \& Rahmadiyanto, C. (2001). Teknologi Paving Block. Yogyakarta: Kanisius.

Siregar, S. (2012). Statistik Parametrik untuk Penelitian Kuantitatif. Jakarta: Bumi Aksara. 